九州大学学術情報リポジトリ

Kyushu University Institutional Repository

\title{
Relative Study of Flow Properties Between Orifice and Nozzle Plates
}

\section{Md. Ariful Islam Shubho}

Department of Aeronautical Engineering, Military Institute of Science and Technology

Rahman, Towsibur

Department of Aeronautical Engineering, Military Institute of Science and Technology

Prof. Dr. M. A. Taher Ali

Department of Aeronautical Engineering, Military Institute of Science and Technology

https://doi.org/10.5109/4738570

出版情報: Proceedings of International Exchange and Innovation Conference on Engineering \& Sciences (IEICES). 7, pp. 84-89，2021-10-21. 九州大学大学院総合理工学府 バージョン：

権利関係: 


\title{
Relative Study of Flow Properties Between Orifice and Nozzle Plates
}

\author{
Md. Ariful Islam Shubho ${ }^{1 *}$, Towsibur Rahman ${ }^{1}$, Prof. Dr. M.A. Taher Ali ${ }^{1}$ \\ ${ }^{1}$ Department of Aeronautical Engineering, Military Institute of Science and Technology, Dhaka, Bangladesh \\ ${ }^{*}$ Corresponding author email: arifulshubho006@gmail.com
}

\begin{abstract}
This research is aimed at developing an experimental system designed to examine the flow of the fluid in the pipe and the fluid velocity. One of the main purposes of the experiment is to calculate the flow nature after sudden pipe expansion. Another purpose of the experiment is to show the losses in terms of velocity and pressure at different points of the open tunnel. Calculating the value of the co-efficient of discharge is also a part of our objective. In this study $C_{d}$ is calculated for both orifice plate and nozzle plate. Overall the main focus of this study is to plot velocity vs distance and pressure vs distance graphs for both orifice plate and nozzle plate and compare them.
\end{abstract}

Keywords: Orifice Plate, Nozzle, Flow Properties, Velocity, Pressure

\section{INTRODUCTION}

For measuring the fluid flow in pipe, an entry nozzle is employed. For studying the essence of movement, an aerodynamic open tunnel is employed. The pressure drop in the pipe is measured to calculate frictional head loss. There are many varieties of losses of head for flowing liquids like friction, inlet and outlet losses. The main loss is that because of frictional resistance of the pipe, which depends on the inner roughness of the pipe. So losses were taken into consideration as a percentage of error. An automated traverse system with a pitot tube produces a velocity profile from the velocity tip. For the analysis of fluid behavior, a flow nozzle within the pipe is employed. For further data analysis similar data for various diameter orifice is calculated. The general orifice used in this study is $1000 \mathrm{~mm}$ and $796 \mathrm{~mm}$ in diameter.

\section{LITERATURE REVIEW}

Differential pressure devices such as orifice plates and nozzles are extensively applied in several industries in order to estimate the mass flow rate running through a conduit by correlating the measured pressure loss and the mass flow rate [1]. Orifice plates are most commonly used for continuous measurement of fluid flow in pipes. They are also used in some small river systems to measure flow rates at locations where the river passes through a culvert or drain. An orifice plate is a device used for measuring the rate of fluid flow. It uses the same principle as a Venturi nozzle, namely Bernoulli's principle which states that there is a relationship between the pressure of the fluid and the velocity of the fluid. When the velocity increases, the pressure decreases and vice versa. An orifice plate is a thin plate with a hole in the middle. It is usually placed in a pipe in which fluid flows [2]. The sensitivity of orifice plate flow meters to the quality of the approaching flow continues to be a cause for concern in flow metering. The distortions caused by pipe fittings such as valves, bends, compressors and other devices located upstream of the orifice plate can lead to non-standard velocity profiles and give errors in measurement. [3]. The slotted orifice flowmeter is superior to the standard orifice flowmeter in maintaining its calibration over a wide range of inlet flow conditions [4]. A nozzle plate, being a key part in steam engines, changes flow directions of steam in a turbine used in power plant [5]. In laminar impinging flow heat transfer it is well known that at small nozzle-to-plate distances the Nusselt number distribution displays an off-stagnation point maxima located one nozzle radius away from the stagnation point [6]. The study of flow field over the bluff body has huge contributions in aerodynamic science [7]. Wind turbines are the conventional method of converting wind energy into mechanical energy, and then into electrical energy. One of the most important factors affecting the dynamics of the turbine, is the turbulence of the wind acting on it [8]. Multi-relaxation time lattice Boltzmann scheme demonstrated good agreement, supports its validity in computing fluid flow problem [9]. Passive flow control is a great way to improve aerodynamic behavior of a wing by delaying boundary layer separation delay [10]. In this experiment, the flow properties i.e. velocity and pressure for both orifice plate and nozzle are measured and compared to provide a relative illustration.

\section{METHODS}

The standard equation used to estimate flow through a small orifice (small infers that the pressure distribution across the orifice can be neglected, i.e., head is high compared to the diameter of the orifice) discharging in atmosphere can be written as-

$$
\mathrm{Q}=\mathrm{C}_{\mathrm{d}} \mathrm{A}_{0} \sqrt{2 \mathrm{~g} \Delta \mathrm{h}}
$$

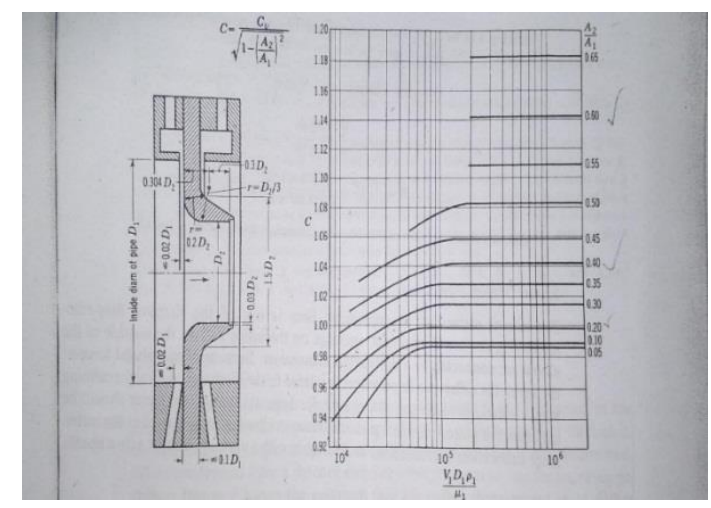

Fig. 1. Flow nozzle and discharge coefficient.

$\mathrm{Q}$ is mass flow rate $\left(\frac{m^{3}}{s}\right)$

$\mathrm{C}_{\mathrm{d}}=$ dimensionless discharge coefficient

$\mathrm{A}_{0}=$ orifice area $\left(\mathrm{m}^{2}\right)$

$\mathrm{g}=$ acceleration due to gravity

$\Delta \mathrm{h}=$ head above the center of the orifice (m)

We know,

Actual flow rate of entry nozzle at a point is,

$$
\mathrm{Q}=\mathrm{AV}
$$

Where, 
$A=$ Area of nozzle cross section at that point

$\mathrm{V}=$ Velocity of flow at that point

\section{CONCEPTUAL DESIGN}

For the development of the concept of the orifice and nozzle plate, a simple graphical work is presented. Here for the nozzle, outer diameter is $110 \mathrm{~mm}$ and inner diameter is $100 \mathrm{~mm}$. In the experiment, for convenience of the comparison between nozzle and orifice, area ratio is selected for both is $0.23,0.38$ and 0.55 . Bevel angle is used for the orifice plate is $33^{\circ}$. Moreover, these specific bevel angle is used to reduce the frictional loss. Inside diameter for the orifice is $78 \mathrm{~mm}$ and outside is $128 \mathrm{~mm}$. Thickness for the nozzle and vacillates slightly. The designs are done using SolidWorks.

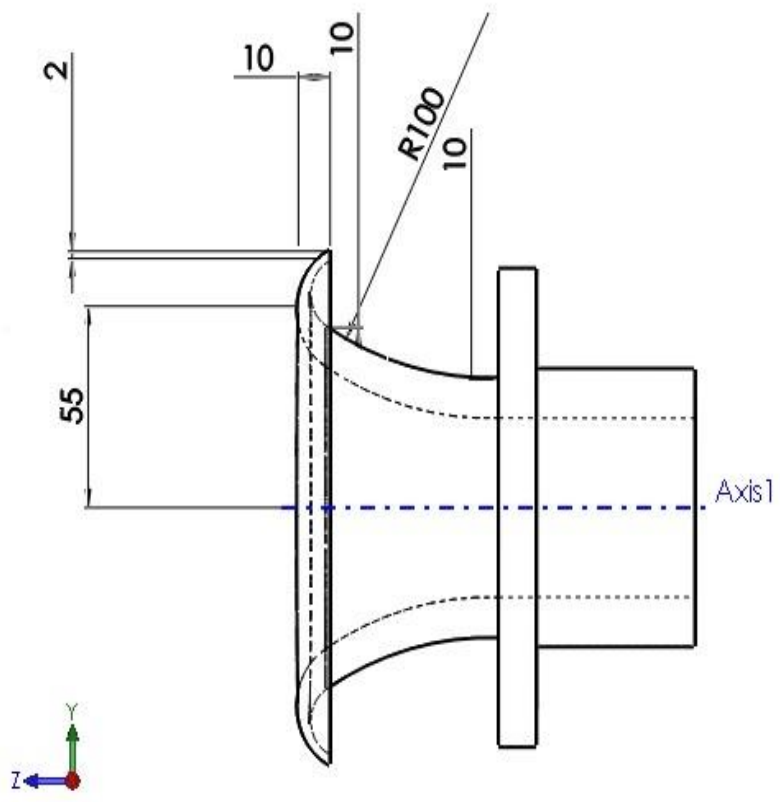

Fig. 2. Conceptual Design of nozzle.

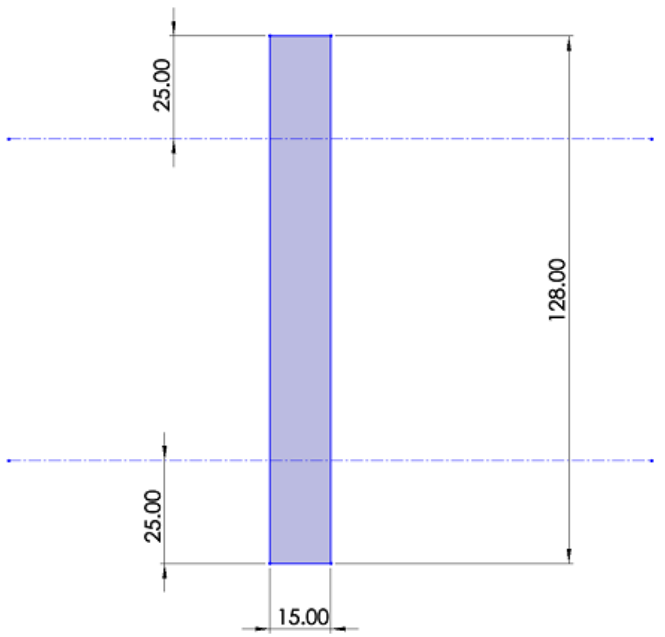

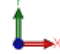

Fig. 3. Conceptual Design of orifice.

\section{HARDWARE AND SET UP}

\subsection{Basic Components}

(1) Nipple Joint: Nipple joints are used for connecting two fittings. In this study nipple joints having diameter of $5 \mathrm{~mm}$ were used.
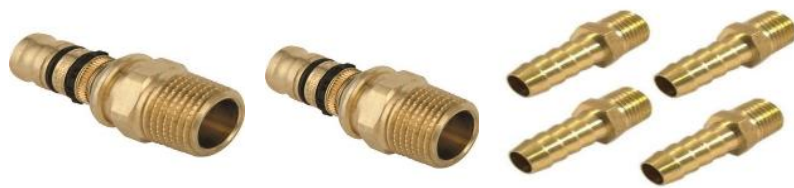

Fig. 4. Nipple Joint.

(2) Manometer: Manometer is used for measuring pressure. Manometers are devices that assign liquid columns for measuring the differences in pressure. The basic principle of manometer is successive column of fluid pressure is equal at the same level.

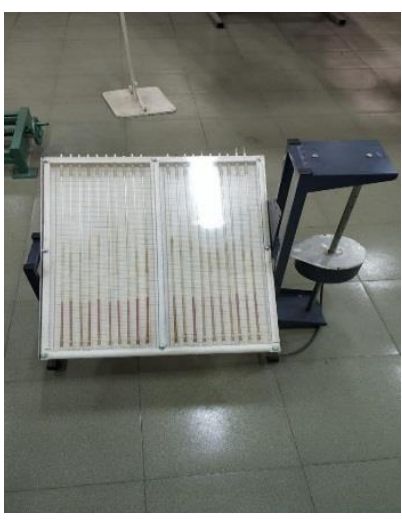

Fig. 5. Manometer. 
(3) Flange: Pipes with flanges can be combined and split up easily.

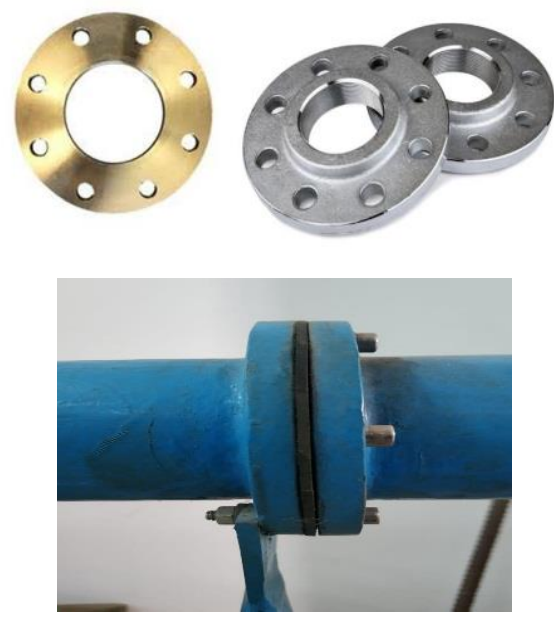

Fig. 6. Flanges.

(4) Gasket: Gasket is a mechanical fastening component that fills the gap between two or more joined surfaces, commonly to restrain leakage from or into the linked objects while under compression.
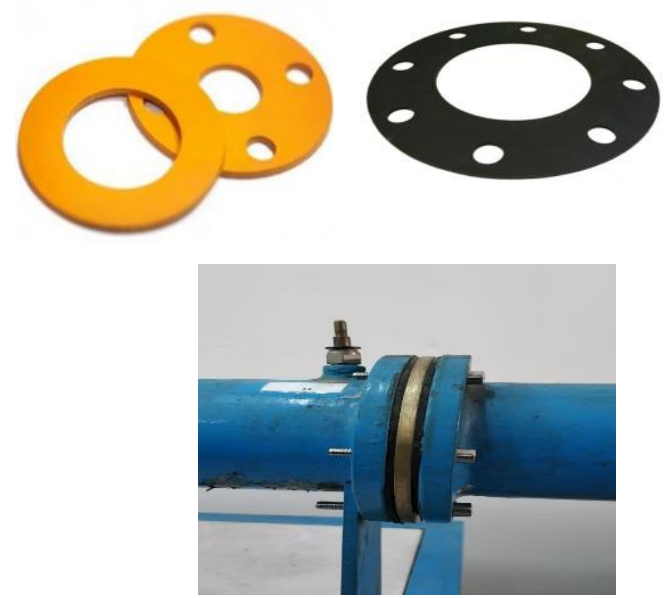

Fig. 7. Gasket.

(5) Blower:

Specification of the blower used:

Outlet area: $183 \times 183 \mathrm{~mm}^{2}$

Power: $1.6 \mathrm{KW}$ (for 3 phases 385 volt)

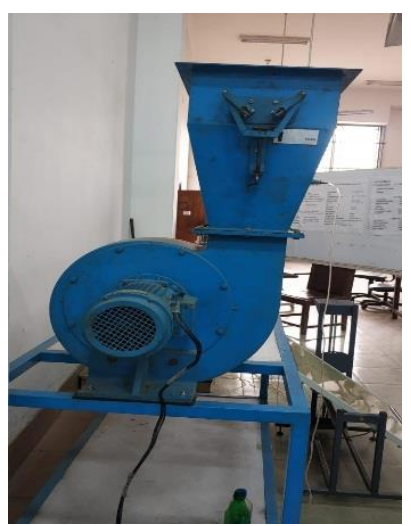

Fig. 8. Blower.

\subsection{Mounting Systems}

Mounting system is composed of mainly 2 parts: Table and Stand

(1) Table: The dimension of the table is 6.5 feet $\times 3.5$ feet $\times 3.5$ feet.

(2) Stand: A stand of 4 feet was used to support the whole set up.

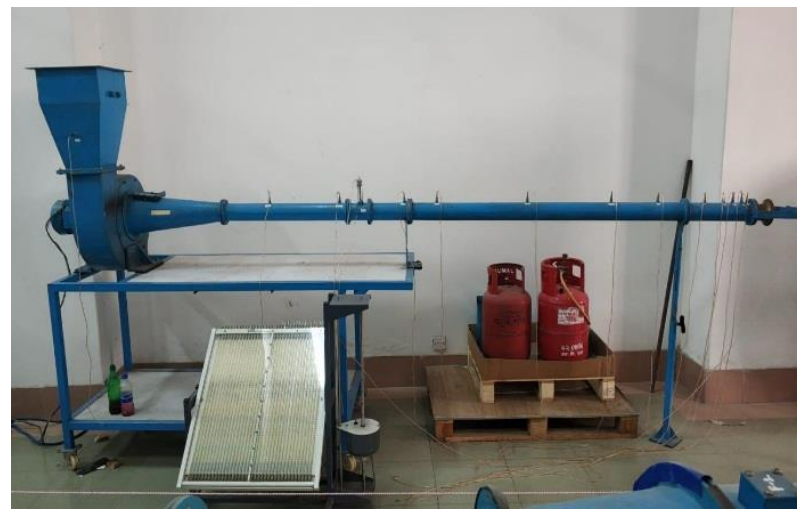

Fig. 9. Complete Set up.

\section{CALCUlation}

Finding out the value of coefficient of discharge from flow rate of entry nozzle (at $140 \mathrm{~mm}$ distance from nozzle inlet) and flow nozzle:

When, outlet valve is fully opened, at that time actual flow rate of entry nozzle at $140 \mathrm{~mm}$ distance from nozzle inlet is,

$$
\begin{aligned}
\mathrm{Q}= & \frac{\pi}{4} \times(0.05)^{2} \times 12 \frac{\mathrm{m}^{3}}{\mathrm{~s}} \\
= & 0.0235 \frac{\mathrm{m}^{3}}{\mathrm{~s}}
\end{aligned}
$$

Referring to the above figure, expression for flow rate through the flow nozzle is given by,

$$
\mathrm{Q}=\mathrm{A}_{2} \times \mathrm{V}_{2}
$$


$\mathrm{V}_{2}=$ average velocity of fluid at nozzle outlet

$=\sqrt{\frac{2 \times g \times 1000 H}{1-\left(\frac{d 2}{d 1}\right)^{4}}}$

$\mathrm{d}_{2}=$ diameter of nozzle outlet

$\mathrm{d}_{1}=$ diameter of pipe

$\mathrm{H}=$ deflection of water manometer

$\mathrm{g}=$ acceleration due to gravity

So, when outlet valve is fully opened flow rate through the flow nozzle is,

$$
\begin{aligned}
Q= & \frac{\pi}{4} \times(0.0396)^{2} \times \sqrt{\frac{2 \times 9.81 \times 1000 \times 0.02}{1-0.0605}} \\
& =0.02517 \frac{\mathrm{m}^{3}}{\mathrm{~s}}
\end{aligned}
$$

Now coefficient of discharge when outlet valve is fully opened,

$$
C_{d}=\frac{0.02757}{0.0235}=1.08
$$

When, valve is fully opened at that time Reynold's number is,

$$
\mathrm{N}_{\mathrm{Re}}=\frac{V 1 d 1 \rho 1}{\mu}
$$

$\mathrm{V}_{1}=\frac{Q}{A 1}=$ velocity of fluid at pipe inlet $=\frac{0.0235}{\frac{\pi}{4} \times(0.075)^{2}}=$ $5.32 \frac{\mathrm{m}}{\mathrm{s}}$

$\mathrm{Q}=$ flow rate of entry nozzle at $140 \mathrm{~mm}$ distance from nozzle when valve is fully opened

$\mu=$ dynamic viscosity of air

So,

$$
\mathrm{N}_{\mathrm{Re}}=\frac{5.32 \times 0.75 \times 1.225}{1.789 \times 10^{-5}}=0.27321 \times 10^{5}
$$

And area ratio of flow nozzle is,

$$
\frac{\mathrm{A} 2}{A 1}=\frac{(0.0396)^{2}}{(0.07982)^{2}}=0.2461
$$

\section{RESULT \& DISCUSSION}

In this experiment, two conditions have been considered to illustrate velocity vs distance and pressure vs distance graphs for both orifice and nozzle plates. In a particular pipe flow, the value of pressure and velocity have been measured. A valve has been used to control the flow of the outlet. The main reason of using the valve is to control the flow of the outlet and make an influence over the outlet velocity and pressure. The first condition is when the valve is fully opened and the second condition is when the valve is fully closed. That means the measurement of both flow properties i.e. velocity and pressure have to be done in these two conditions in the outlet using orifice plate and nozzle plate and make a relative illustration between them by plotting their values in graphs simultaneously.

\subsection{Pressure vs. Distance (when the valve is fully opened)}

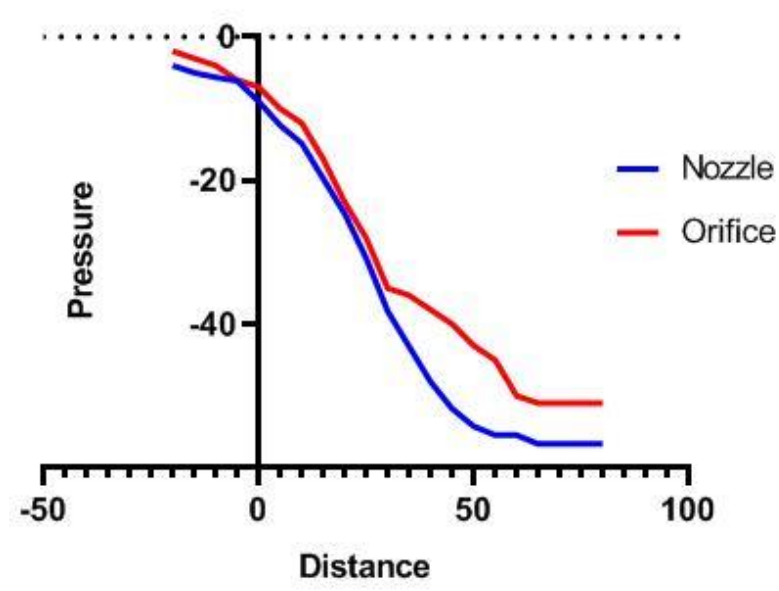

Fig. 10. Variation of pressure when valve is open.

When the valve is fully opened, the outlet pressure is not being influenced. While measuring the pressure, the inlet values have been ignored and only convergent nozzle has been used. Outlet pressure for both orifice plate and nozzle have been plotted for different points at the outlet. From the graph, it can be seen that at the origin the difference between pressures of both component is very much negligible. As soon as the fluid flow reaches the outlet there seems to be a little difference between pressures of both components. At $35 \mathrm{~cm}$ distance the pressure of the orifice plate starts to rise and after $35 \mathrm{~cm}$ it increases drastically. This increment is continued for the last distance measurement taken which is $80 \mathrm{~cm}$. The overall outlet pressure of orifice plate is significantly higher than that of nozzle.

\subsection{Velocity vs. Distance (when the valve is fully opened)}

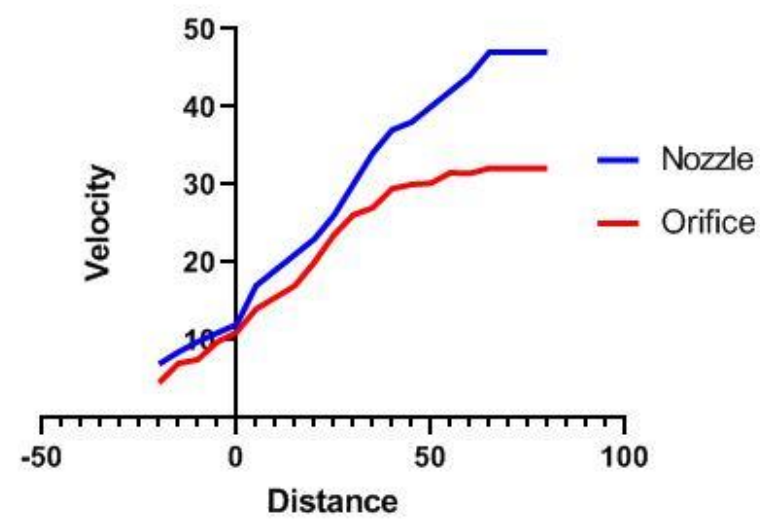

Fig. 11. Variation of velocity when valve is open.

When the valve is fully opened, the outlet velocity is not being influenced. While measuring the velocity, the inlet values have been ignored and only convergent nozzle has 
been used. Outlet velocity for both orifice plate and nozzle have been plotted for different points at the outlet. From the graph, it is seen that at origin the velocity difference is not that significant. But as soon as the flow enters the outlet area the velocity difference becomes significant between orifice plate and nozzle. And at 35 $\mathrm{cm}$ distance the velocity of nozzle increases even more and after $35 \mathrm{~cm}$ flow velocity through nozzle increases drastically. And overall the velocity of nozzle is much higher than that of orifice plate.

\subsection{Pressure vs. Distance (when the valve is fully closed)}

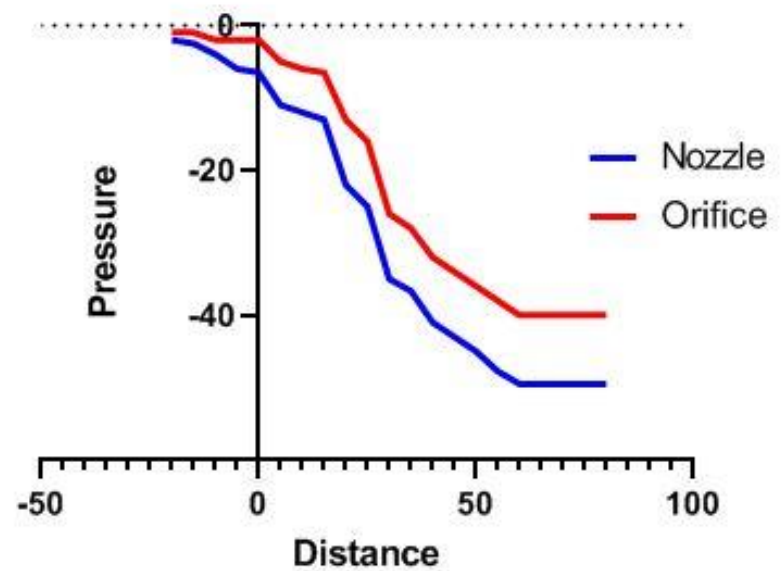

Fig. 12. Variation of pressure when valve is closed.

In this condition, the valve is closed for affecting the pressure and finding out the impact in a graphical way. All the previous situations are kept alike while the only differential impact was provided through the closed valve. The outlet pressure in the closed valve situation for both orifice plate and nozzle have been calculated and plotted in a graph to find out the impact and it should be compared with open valve situation. So, when the valve is closed the inlet pressure is still ignored. Pressure difference at the origin is still not significant. But as the flow approaches the outlet, the effects start to unveil. For closed valve condition, the effects start to show up at an early stage and at a much less distance. As soon as the flow reaches $20 \mathrm{~cm}$ distance the pressure difference for both the components tend to change where the pressure rise of orifice plate is obviously higher but after $20 \mathrm{~cm}$ the value of pressure rises drastically for the orifice plate and the overall pressure curve of orifice plate is much higher than that of nozzle. But if we consider the valve condition, then it is evident that the pressure values for both orifice plate and nozzle have risen up for closed valve. The pressure curve for nozzle has risen in closed valve situation compared to the low curve in open valve. Same thing has happened to the pressure curve of orifice plate. The valve when closed put a significant deal of impact over the outlet pressure which led to the overall pressure rise for both components. Though, the pressure difference between orifice plate and nozzle remain alike, their overall pressure has risen up compared to the open valve condition.
7.4 Velocity vs. Distance (when the valve is fully closed)

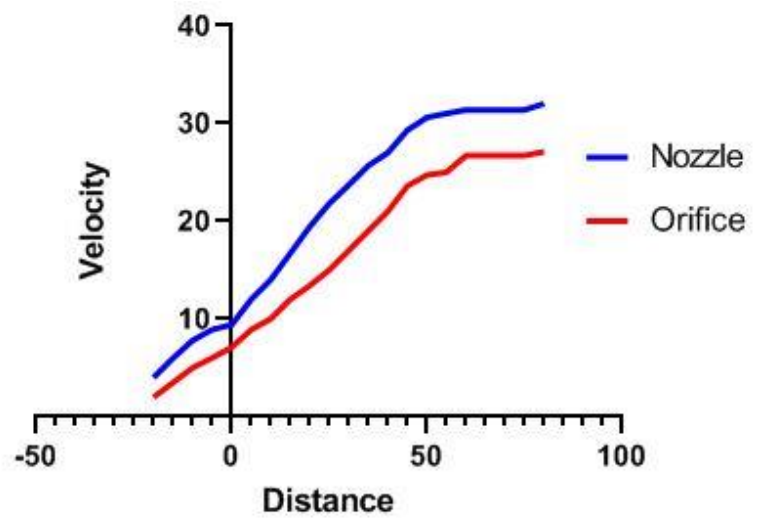

Fig. 13. Variation of velocity when valve is closed.

In this condition, the valve is closed for affecting the velocity and finding out the impact in a graphical way. All the previous situations are kept alike while the only differential impact was provided through the closed valve. The outlet velocity in the closed valve situation for both orifice plate and nozzle have been calculated and plotted in a graph to find out the impact and it should be compared with open valve situation. So, when the valve is closed the inlet velocity is still ignored. Velocity difference at the origin is still not significant. But as the flow approaches the outlet, the effects start to take place. For closed valve condition, the effects start to show up at an early stage and at a much less distance. As soon as the flow reaches $15 \mathrm{~cm}$ distance the flow velocities for both the components tend to change where the increase in velocity of nozzle is definitely higher but after $15 \mathrm{~cm}$ velocity increases drastically for the nozzle and the overall velocity curve of nozzle is much higher than that of orifice plate. But if we consider the valve condition, then it is clear that the velocities for both nozzle and orifice plate have decreased for closed valve. The velocity curve for orifice plate has descended in closed valve situation compared to the higher curve in open valve. Same thing has happened to the velocity curve of nozzle. The valve when closed put a significant deal of impact over the outlet velocity which led to the overall velocity descend for both components. Though, the velocity difference between nozzle and orifice plate remain alike, their overall velocity has decreased compared to the open valve condition.

\section{RECOMMENDATION}

The setup can be made more stable through better mounting system. Through studying and controlling flow properties flow through a pipe can be improved in future. This study can be useful in studying the co-efficient of discharge of any fluid flowing through a pipe. Future application may include the improvement of co-efficient of discharge and the overall flow property eventually a much developed flow through pipe system.

\section{CONCLUSION}

The main target of this this study has been to find out the relation between pressure and velocity for orifice plate and nozzle in two different conditions. At the same time, 
to find out the difference between the flow properties curve of this two items have also been an objective. The two conditions consist of open valve and closed valve conditions. Generally, in flow through orifice plate in a pipe the pressure remains greater than flow through nozzle. And in flow through nozzle the velocity remains higher than flow through orifice plate. This happens because of the inversely proportional relation between velocity and pressure. Theoretically, velocity and pressure have inverse proportional relation i.e. with the increment in pressure velocity decreases and vice versa. In this experiment, the practical result agrees with the theory. This theory is fully obliged in the open valve condition. For closed valve situation, the scenario does not change but there are some impacts which need to be considered. When the valve is closed it affects the outlet flow properties. For the closed valve, the outlet pressure increases and outlet velocity tends to decrease. So, when the valve is closed pressure for both orifice plate and nozzle plate rises. The rise is significantly higher than the open valve condition for both. Same thing happens for velocity as well but in the opposite way. As pressure rises, so the velocity decreases. But the descend happens for both nozzle plate and orifice plate. So, the theory is justified in this condition also. The overall findings are that pressure and velocity difference between nozzle plate and orifice plate is not affected in any condition. But their individual increment and decrement in both pressure and velocity happens in the closed valve condition.

\section{REFERENCES}

[1] Imada, F. H. J., F. Saltara, and J. L. Baliño. "Numerical determination of discharge coefficients of orifice plates and nozzles." 22nd International Congress of Mechanical Engineering (COBEM 2013). 2013.

[2] Peter, Ukpaka Chukwuemeka, and Ukpaka Chinedu. "Model prediction for constant area, variable pressure drop in orifice plate characteristics in flow system." Chem. Int 2.8 (2016): 80-88.

[3] Manshoor, Bukhari bin, F. C. G. A. Nicolleau, and S. B. M. Beck. "The fractal flow conditioner for orifice plate flow meters." Flow Measurement and Instrumentation 22.3 (2011): 208-214.

[4] Morrison, Gerald L., et al. "Comparison of orifice and slotted plate flowmeters." Flow measurement and Instrumentation 5.2 (1994): 71-77.

[5] Jung, Jong Yun, Heesung Park, and Joon-Seob Kim. "Structural Safety of Nozzle Plate using Simulation." Journal of the Society of Korea Industrial and Systems Engineering 41.3 (2018): 186-193.

[6] Chatterjee, Ajay, and L. J. Deviprasath. "Heat transfer in confined laminar axisymmetric impinging jets at small nozzle-plate distances: the role of upstream vorticity diffusion." Numerical Heat Transfer: Part A Applications 39.8 (2001): 777-800.

[7] Rahman, Towsibur, and Ariful Islam. "Determination of Flow Characteristics and Performance Analysis of the Non-Rotating \& Rotating Cylinder." Sciences (IEICES) 6 (2020): 271-276.

[8] Ismaiel, Amr MM, and Shigeo Yoshida. "Study of turbulence intensity effect on the fatigue lifetime of wind turbines." Proceedings of International Exchange and Innovation Conference on Engineering \& Sciences (IEICES). No. 3. Interdisciplinary Graduate School of Engineering Sciences, Kyushu University, 2017.

[9] Sidek, Nor Azwadi Che, and Aman Ali Khan. "Experimental and Numerical Simulation Investigation of Flow Over a Cavity Using MultiRelaxation Time Lattice Boltzmann Method." Proceedings of International Exchange and Innovation Conference on Engineering \& Sciences (IEICES). No. 2. Interdisciplinary Graduate School of Engineering Sciences, Kyushu University, 2016.

[10] Zafi, Nogib Anwar, Md Afjal Hossain, and Md Taohid Islam Mim. "Experimental Study of NACA 0012 Airfoil with Slanted Drills Through the Body." Proceedings of International Exchange and Innovation Conference on Engineering \& Sciences (IEICES). No. 6. Interdisciplinary Graduate School of Engineering Sciences, Kyushu University, 2020. 